\title{
"Ainda assim me levanto "1": as narrativas históricas e a construção do eu feminino
}

\section{"Still I rise": historical narratives and the construction of feminine self}

\section{"Aún así me levanto": las narrativas históricas y la construcción del yo femenino}

\author{
Ana Carolina Cerqueira Medrado* \\ Universidade Federal da Bahia - UFBA, Salvador, Bahia, Brasil \\ Mônica Lima de Jesus** \\ Universidade Federal da Bahia - UFBA, Salvador, Bahia, Brasil
}

\begin{abstract}
RESUMO
Este ensaio objetiva discutir duas narrativas concorrentes sobre o eu feminino (uma construída pelo patriarcado, produzida, sobretudo, pelos discursos médicos-científicos durante o século XIX e outra que apresenta a resistência feminina frente às opressões patriarcais), bem como analisar as repercussões de ambas as narrativas na construção do eu e na saúde mental das mulheres. Adotamos como referencial teórico a Psicologia Social Construcionista e o Feminismo Interseccional. A Psicologia Social Construcionista concebe o eu como um recurso discursivo, situado histórica, social e culturalmente. Nesse sentido, recusa tanto uma visão essencialista sobre o eu e sobre o feminino quanto a proposta individualista de construção do eu. Assume que a construção do eu ocorre com narrativas inteligíveis sobre si mesmo e, nessa construção, narrativas históricas também se fazem presentes. Assim, os discursos construídos historicamente pela ciência, especialmente a ciência médica, participam da construção do eu, inclusive da performance de gênero. Compreendemos as narrativas como produtoras de subjetividades; devido a isso, reconhecemos a importância de destacar as narrativas paralelas, que salientam a resistência feminina. Ademais, a retomada histórica permite perceber que determinadas crenças, valores e preconceitos foram estabelecidos historicamente e, sendo assim, outras narrativas também são possíveis.
\end{abstract}

Palavras-chave: eu, gênero, história, narrativas, Psicologia Social Construcionista.

\section{ABSTRACT}

This essay aims to discuss two competing narratives about the feminine self (one built by patriarchy, especially that produced by medical-scientific discourses during the nineteenth century; and another that presents the feminine resistance against the patriarchal oppressions), as well as to analyze the repercussions of both narratives in the construction of self and women's mental health. We adopted as theoretical reference Social 
Constructionist Psychology and Intersectional Feminism. Social Constructionist Psychology conceives the self as a discursive resource, historically, socially and culturally situated. In this sense, it refuses both an essentialist view of the self and the feminine, as well as the individualistic proposition of self-construction. It assumes that the construction of the self occurs with intelligible narratives about the self, and in this construction, historical narratives are also present. Thus, discourses constructed historically by science, especially medical science, participate in the construction of the self, including the performance of gender. We understand the narratives as producers of subjectivities, because of this we recognize the importance of highlighting the parallel narratives, which emphasize the feminine resistance. In addition, the historical resumption allows us to realize that certain beliefs, values and prejudices were established historically and, thus, other narratives are possible.

Keywords: self, gender, history, narratives, Social Constructionist Psychology.

\section{RESUMEN}

Este ensayo objetiva discutir dos narrativas concurrentes sobre el yo femenino (una construida por el patriarcado, producida, especialmente, por los discursos médicos-científicos durante el siglo XIX; y otra que presenta la resistencia femenina frente a las opresiones patriarcales), así como analizar las repercusiones de ambas narrativas en la construcción del yo y la salud mental de las mujeres. Adoptamos como referencial teórico la Psicología Social Construccionista y el Feminismo Interseccional. La Psicología Social Construccionista concibe el yo como un recurso discursivo, históricamente, socialmente y culturalmente situado. En ese sentido, rechaza tanto una visión esencialista sobre el yo y sobre lo femenino, como la propuesta individualista de construcción del yo. Se asume que la construcción del yo ocurre con narrativas inteligibles sobre el sí mismo y, en esa construcción, narrativas históricas también se hacen presentes. Así, los discursos construidos históricamente por la ciencia, sobre todo la ciencia médica, participan en la construcción del yo, incluso de la performance de género. Comprendemos las narrativas como productoras de subjetividades; debido a eso, reconocemos la importancia de destacar las narrativas paralelas, que subrayan la resistencia femenina. Además, la reanudación histórica permite percibir que determinadas creencias, valores y prejuicios fueron establecidos históricamente y, por lo tanto, otras narrativas también son posibles.

Palabras-clave: yo, género, historia, narrativas, Psicología Social Construccionista.

Você pode me fuzilar com palavras

E me retalhar com seu olhar Pode me matar com seu ódio Ainda assim, como o ar, vou me levantar (Maya Angelou) $^{2}$

Começamos este ensaio com o poema de Maya Angelou, poeta negra, porque queremos contar outra história das mulheres. Uma história para além do silenciamento, da opressão e da subjugação. Queremos 
falar da resistência das mulheres, a qual se faz em uma luta conjunta, coletiva.

Assim, objetivamos: 1) discutir duas narrativas concorrentes sobre 0 eu feminino, uma construída pelo patriarcado, produzida, sobretudo, pelos discursos médicos-científicos durante o século XIX; e outra que apresenta a resistência feminina frente às opressões patriarcais; 2) analisar as repercussões de ambas as narrativas na construção do eu e na saúde mental das mulheres. Para tanto, nos valemos de uma revisão bibliográfica, tendo como referencial a Psicologia Social Construcionista (notadamente, o autor Kenneth Gergen) e do feminismo interseccional, destacando as interseções entre gênero, raça e classe social.

A interseccionalidade, que foi popularizada por Kimberlé Crenshaw (2002), é definida por ela como:

[...] conceituação do problema que busca capturar as consequências estruturais e dinâmicas da interação entre dois ou mais eixos da subordinação. Ela trata especificamente da forma pela qual o racismo, o patriarcalismo, a opressão de classe e outros sistemas discriminatórios criam desigualdades básicas que estruturam as posições relativas de mulheres, raças, etnias, classes e outras. Além disso, a interseccionalidade trata da forma como ações e políticas específicas geram opressões que fluem ao longo de tais eixos, constituindo aspectos dinâmicos ou ativos do desempoderamento (Crenshaw, 2002, p. 177).

Desse modo, assumem-se as diferenças entre os gêneros, raças, classes, entre outras, presentes em nossa sociedade, porém, ao invés de tratar as diferenças por uma perspectiva de marginalização das minorias, a interseccionalidade utiliza-as como marca de afirmação na busca da garantia de direitos. Ressalta ainda que a interação entre tais diferenças produz outros tipos de diferença, o que significa dizer que as opressões que uma mulher branca sofre nunca serão iguais àquelas sofridas pelas mulheres negras. As experiências das mulheres, negros, LGTBQ+ não são monolíticas e um suposto discurso de igualdade escamoteia as diversas discriminações a que cada uma dessas pessoas é exposta em seu cotidiano.

Salientamos que o recorte histórico que adotamos não visa delimitar um período histórico ou espaço geográfico, pois nosso intuito é desfamiliarizar uma suposta essência feminina, discutindo como nossa visão sobre o "ser mulher" não é natural, mas foi/está sendo alicerçada histórica e socialmente. Conforme Mary Spink e Rose Frezza (2013), novos conteúdos ocorrem em paralelo com os antigos, que são constantemente revisitados e renovados; por isso, as autoras creem que é mais adequado desfamiliarizar conteúdos do que 
desconstruí-los, já que nada de fato é "des-construído". Dessa forma, compreendemos que as narrativas históricas que produzimos transitam no tempo e no espaço, não se encerram em um dado marco histórico, mas são constantemente retomadas lado a lado com novas narrativas.

\section{As narrativas e a construção do eu: uma leitura da Psicologia Social Construcionista}

O construcionismo social é um movimento crítico à ciência positivista e se alinha às discussões da pós-modernidade. Tem como principais premissas: a compreensão da realidade como socialmente e historicamente construída; o antiessencialismo; o antirrealismo; o antirepresentacionismo; a ênfase na linguagem, compreendida como produzida a partir das interações sociais e como construtora da realidade; o questionamento contínuo da "verdade"; o conhecimento encarado como histórico e socialmente contextualizado; a nãoneutralidade científica (Castañon, 2004; Méllo, Silva, Lima, \& Di Paolo, 2007; Rasera \& Japur, 2005).

A demarcação de uma autoria e origem do movimento ocorre de maneira nebulosa. O próprio Kenneth Gergen, visto frequentemente como fundador do movimento construcionista na Psicologia Social, descarta a ideia de delimitação de autoria ou de marco histórico para - surgimento do construcionismo, porque esse deve ser compreendido como uma produção coletiva (Rasera \& Japur, 2005). Ademais, o fundacionismo é contraditório à proposta construcionista (Gergen, 2011).

Entretanto, podemos identificar as influências de três movimentos críticos à ciência para o seu aparecimento: a crítica ideológica, a crítica literário-retórico e a crítica social. Todos esses movimentos põem em suspeição o estatuto empirista e realista de verdade científica. Questionam, inclusive, as separações disciplinares e têm sido identificados como giro pós-moderno (Gergen, 2011).

A psicologia social construcionista opõe-se ao individualismo da psicologia, propondo uma psicologia com ênfase nas construções sociais, 0 que se reflete, inclusive, na concepção de eu construcionista. Para o construcionismo, o eu é um recurso discursivo, o que significa dizer que ele se constrói e se expressa pela linguagem, ele não está enclausurado dentro das pessoas. A mesma concepção pode ser estendida para a memória: ela não é um evento privado, rememorar é a capacidade de construir uma narrativa inteligível sobre um determinado acontecimento. É a construção e preservação de tais narrativas no intercâmbio social que permitem que um povo se reconheça como participante de um dado contexto cultural (Gergen 1998, 2001). 
Compreender o eu como construído socialmente é ainda reconhecê-lo como culturalmente e historicamente situado. Nessa medida, é válido recorrermos à divisão do tempo delineada por Spink e Medrado (2013), que identificam três tempos históricos: o tempo longo, o tempo vivido e o tempo curto. O tempo longo é aquele que se refere à história da civilização, o tempo vivido é aquele da história de socialização da pessoa e o tempo curto alude às interações cotidianas. Assim, a construção do eu ocorre no decorrer da passagem de tais demarcações históricas, seja como conceito, seja como produção identitária da pessoa.

Para compreender a concepção de eu construcionista é preciso discorrer sobre narrativa. A narrativa vai além de um mero contar histórias, ela constrói a identidade de um povo, de um grupo, de um sujeito: "Vistas dessa maneira, as narrativas são ao mesmo tempo modelos do mundo e modelos do self. É através de nossas estórias que construímos a nós mesmos como parte de nosso mundo" (Brockmeier \& Harré, 2003, p.533).

Nesse sentido, a narrativa é assumida como uma forma peculiar de discurso e, sendo assim, não é um atributo da mente individual, mas é produzida em interação social, bem como constrói a realidade (Brockmeier \& Harré, 2003; Gergen, 1998). Conforme Jens Brockmeier e RomHarré (2003):

[...] as narrativas não devem ser concebidas como a apresentação de uma versão externa de entidades mentais particulares, pairando em um tipo de condição pré-semiótica. Apresentar algo como uma narrativa não significa externalizar algum tipo de realidade interna nem oferecer uma delimitação linguística para essa tal realidade. Ao contrário, narrativas são formas inerentes em nosso modo de alcançar conhecimentos que estruturam a experiência do mundo e de nós mesmos. Em outras palavras, a ordem discursiva através da qual nós tecemos nosso universo de experiências emerge apenas como um modus operandi do próprio processo narrativo. Ou seja, estamos lidando primariamente não com um modo de representação, mas com um modo específico de construção e constituição da realidade [...] (p.531).

Kenneth Gergen (1998, 2011) afirma que a narrativa vem se transformando no decorrer da história da humanidade e é produzida em vários domínios sociais: na literatura, na ciência, na história, entre outros. A narrativa não é livre, ela assume algumas características para que seja inteligível socialmente: delimitação de um objetivo, de algo a ser contado; seleção de eventos relevantes de acordo com a história a ser contada; ordenação dos eventos, que tende a seguir uma cronologia linear; estabilidade da identidade, uma 
narrativa típica deve oferecer uma estabilidade do sujeito ou do objetivo sobre o qual se narra; explicações causais, um evento levando/causando outro; signos que demarcam início, fim e desenrolar da narrativa (Gergen, 1998, 2011). É importante salientar que tais características são socialmente construídas, não se dão por si.

Se a narrativa constrói o mundo, é através das autonarrativas que o sujeito constrói a si mesmo:

Al desarrollar una autonarrativa establecemos unas relaciones coherentes entre acontecimientos vitales (Cohler, 1982; Kohli, 1981). En lugar de ver nuestra vida como simplemente "una maldita cosa tras otra", formulamos un relato en el que los acontecimientos de la vida son referidos sistemáticamente, y hechos inteligibles por el lugar que ocupan en una secuencia o "proceso de desarrollo" (de Waele e Harré, 1976). Nuestra identidad presente es, por consiguiente, no un acontecimiento repentino y misterioso, sino un resultado sensible de un relato vital. (Gergen, 2011, p. 233).

Contudo, essa autonarração não é um solilóquio. Eu narro meu eu para um outro e é o seu caráter relacional que fará com que o sujeito aprimore cada vez mais sua autonarração e, dessa maneira, a própria interação social também se incrementa. Ademais, a narrativa cria uma comunidade moral, dificilmente a narrativa de um sujeito envolve só ele. A minha ação, a minha história, precisa ser confirmada pelos outros, socialmente, depende dos outros, carece de papéis de apoio para se manter. Desse modo, não é só a narrativa que é interdependente, o sentido de eu também (Gergen, 1998).

A construção do eu a partir das narrativas também é válida para as performances de gênero. Nesse sentido: "A ciência e os meios de comunicação social construíram uma narrativa poderosa: que o gênero é diferença e que a diferença é estática, bipolar e categorial" (Nogueira, 2001, p. 16). O gênero, pela perspectiva da Psicologia Social Construcionista, foge de uma concepção essencialista; é compreendido como fruto das interações sociais, não está "dentro" das pessoas, relaciona-se ainda com a distribuição de poder e acesso a recursos na sociedade (Nogueira, 2001, 2012).

\section{O eu feminino: uma narrativa construída pelo patriarcado}

No ensaio Uma breve história do silêncio, Rebecca Solnit (2017) aborda os diversos tipos de silenciamento aos quais as mulheres foram (e são) submetidas ao longo da história: ser desacreditadas quando denunciam uma violência, crescerem crendo que 
determinados espaços não lhes pertencem, aprenderem a não incomodar, não terem domínio sobre o próprio corpo, não terem direito à educação, ou serem agredidas por contestarem essas assertivas (Solnit, 2017). Um espancamento, um estupro coletivo, ou a última forma de silenciamento: o feminicídio; todos recursos para calar mulheres ou puni-las por se atreverem a falar. Foi para calar sua voz que o talibã alvejou Malala Yousafzai (2013), a garota que lutou pelo direito ao estudo para as meninas no Paquistão. Foi para calar sua voz que Marielle Franco, vereadora no Rio de Janeiro, morreu vítima de um extermínio no primeiro trimestre de 2018.

Michelle Perrot (2008) também fala do silenciamento da história das mulheres por essas serem confinadas à esfera privada. Os grandes fatos históricos ocorreram no espaço público, destarte esse loci mereceu maior atenção dos historiadores. Além disso, ocorreu também o apagamento dos vestígios femininos da história pelo fato de as mulheres não levarem o próprio sobrenome. Outros fatores que contribuíram/contribuem para a escassa produção sobre a participação das mulheres na história foram a alfabetização tardia delas no decorrer da história e a destruição das fontes: elas destruíam os próprios diários e seus outros tipos de escritos por atribuírem pouca importância, era ainda uma maneira de resguardar suas memórias por conta de uma série de pudores (Perrot, 2008).

Assim, de acordo com Shotter e Logan (1993), na construção do eu feminino, as mulheres não dispõem/dispuseram de narrativas próprias que forneçam/fornecessem elementos sobre si mesmas, tudo o que conhecem/conheceram sobre seu eu surge/surgiu do que foi e, em certa medida ainda é, alicerçado pelos homens historicamente.

A demarcação histórica feita aqui não tem o intuito de demarcar um período histórico específico, senão salientar que a discussão sobre um eu feminino foi construída, o que refuta uma proposta essencialista, de que a mulher teria uma essência interna que diverge da masculina; mas, em concordância com a Psicologia Social Construcionista, que enxerga o eu feminino como uma construção histórica e socialmente situada na dinâmica de interações sociais. Diversos estudos (Engel, 2008; Oliveira \& Jacó-Vilela, 2017; Perrot, 2008; Rohden, 2012; Shotter \& Logan, 1993; Solnit, 2017; YoungEisendrath, 1993) têm discutido a construção da polaridade entre os gêneros, desfamiliarizando as concepções tidas como naturais das diferenças entre homens e mulheres, demonstrando assim que uma perspectiva androcêntrica da história e da ciência edificou a hierarquia entre os gêneros/sexos.

$\mathrm{Na}$ filosofia grega, por exemplo, Aristóteles afirmou que as mulheres são um projeto inacabado dos homens, próximas ao mundo animal e que sua função social seria meramente a reprodução (Perrot, 2008). A influência do pensamento aristotélico sobre a diferença entre os 
sexos reapareceu em Tomás de Aquino e nos filósofos iluministas, que também insistiram na inferioridade feminina: Rousseau acreditava que a educação feminina deveria ocorrer apenas para a mulher melhor servir ao homem (Perrot, 2008).

No século XIX, com o advento das ciências médicas, o corpo passou a ser sexualizado, em especial o corpo feminino (Perrot, 2008). A possibilidade de devassar o corpo feminino, de conhecê-lo internamente com o método científico, permitiu uma distinção mais marcada entre homens e mulheres, alicerçando, de igual modo, a construção da subjetividade de ambos por esse mesmo saber científico.

Fabíola Rohden (2012) ratifica o quanto a medicina participou dessa construção. Pesquisando as teses desenvolvidas entre os anos de 1833 e 1840 na Faculdade de Medicina do Rio de Janeiro, ela constatou que $22,3 \%$ delas referiam-se à sexualidade e à reprodução, totalizando 1593 teses sobre as citadas temáticas. Desse total, 1345 referiam-se à mulher e 248 ao homem. A autora destaca que, embora as funções reprodutivas ocorram em maior parte no corpo da mulher (o que justificaria em parte a disparidade entre a divisão das teses) não havia um interesse por parte dos médicos sobre o estudo dos órgãos sexuais masculinos em si e sobre sua participação na reprodução. A autora discute ainda a definição da especialidade ginecologia, que é reconhecida, grosso modo, como o estudo da mulher, o que resume a mulher aos seus órgãos sexuais. Destarte,

[...] podemos sugerir que a medicina e, em particular, as especialidades dedicadas à mulher e à reprodução se convertem em uma verdadeira "ciência da diferença". O argumento central, que perpassa boa parte dos trabalhos da época e também justifica as intervenções concretas, diz respeito a uma distinção natural, de caráter biológico e predeterminado entre os sexos. Homens e mulheres seriam naturalmente distintos nas suas características morais ou psicológicas. Além disso, as qualidades atribuídas a cada um e as suas funções sociais são descritas com o mesmo grau de determinismo que suas funções fisiológicas. O gênero parecia irremediavelmente colado ao sexo a partir de uma única e invariável direção (Rohden, 2012, p. 78-79).

A relação entre a cultura e a natureza nos discursos médicos estudados por Rohden (2012) desvela as contradições desse discurso. Ao mesmo tempo em que tal discurso tenta delimitar uma diferença meramente biológica entre homens e mulheres, também reconhece que a integridade biológica pode ser maculada por questões culturais. Assim, uma menina que lê muitos romances, que é "exageradamente 
educada", que participa da vida urbana pode transgredir seu desenvolvimento como mulher, o que se limitaria à sua capacidade reprodutiva e ao seu papel de boa esposa. As teses estudadas ratificavam que as meninas tinham a inteligência comprometida quando comparada aos meninos, insistir em sua educação seria desperdiçar sua energia, o que afetaria o seu amadurecimento reprodutivo e ainda implicaria em doenças nervosas (Rohden, 2012). Dessa maneira, encontrava-se uma justificava natural para o controle social das mulheres com ecos até os dias atuais.

Oliveira e Jacó-Vilela (2017) desenvolveram estudo semelhante ao de Rohden (2012), realizando levantamento das teses da Faculdade de Medicina do Rio de Janeiro no período compreendido entre 1903 a 1910. Como resultado, encontraram que $10 \%$ das teses se referiam à saúde da mulher e, assim como na pesquisa de Rohden (2012), a biologia aparecia como determinante na compreensão dos papéis sexuais. Ademais, práticas higienistas, respaldadas pela ciência médica, eram usadas para enclausurar a sexualidade feminina.

Também sobre a relação natureza/cultura e feminino/masculino no século XIX, Engel (2008) também afirma que a mulher, nesse período histórico, era vista como ligada à natureza, em contraposição ao homem, que era atrelado à cultura. Sobre a influência médica na construção do eu feminino, Engel (2008) aborda a contribuição da psiquiatria na definição da feminilidade. Aqui percebe-se como o suposto "desvio da natureza feminina" descrito pelas teses investigadas por Rohden (2012) serviu também para construir os padrões de normalidade atrelados a um processo de disciplinarização e medicalização dos corpos femininos.

Engel (2008) discorre ainda sobre a prática da psiquiatria no século XIX, no Brasil, momento no qual os transtornos mentais nas mulheres podiam ser justificados por distúrbios uterinos e menstruações desreguladas, dando motivos para intervenções no aparelho sexual como cirurgias no útero e extirpação do clitóris. Falta de afeição ao marido e aos filhos, bem como "sexualidade exacerbada", dissociada das funções reprodutivas, eram vistas como sintomas psicopatológicos. A dicotomia feminino/natureza e masculino/cultura valia ainda para definir as bordas dos transtornos mentais entre homens e mulheres: o transtorno masculino concernia àqueles que não correspondiam ao papel social de provedor, trabalhador; já a mulher que fugia à sua função de mãe e esposa definida pela natureza era tida como antinatural, se aproximando de um diagnóstico de transtorno mental (Engel, 2008). Demarca-se que, diferente do homem, o transtorno mental se encontrava "dentro da mulher":

[...] no organismo da mulher, na sua fisiologia específica estariam inscritas as predisposições à doença mental. A 
menstruação, gravidez e o parto seriam, portanto, os aspectos essencialmente priorizados na definição e no diagnóstico das moléstias mentais que afetavam mais frequentemente ou de modo específico as mulheres [...]. De acordo com os valores e padrões predominantes nos enfoques psiquiátricos do corpo e da sexualidade femininos, a mulher estaria mais próxima da loucura que os homens (Engel, 2008, p. 334-335).

Entre as características naturais atribuídas às mulheres estava a própria ambiguidade: ao passo em que eram vistas como doces, frágeis, submissas; eram também consideradas perigosas, manipuladoras, sedutoras. Eram reconhecidas tanto por suas características positivas quanto negativas. Essa ambiguidade desafiava a própria ciência que considerava a gravidez tanto como cura quanto como causa das doenças mentais (Engel, 2008).

Uma ciência controlada por homens e que interditava a voz feminina foi capaz de crer na inexistência do prazer sexual da mulher. $O$ orgasmo feminino era visto com estranheza, só sendo concebido em corpos habitados por algum tipo de distúrbio, como a ninfomania, o que poderia justificar a internação dessas mulheres em manicômios (Engel, 2008). Por outro lado, parte dos médicos creditava ao orgasmo feminino a sanidade mental das mulheres, sendo 0 matrimônio encarado como fim terapêutico por conta disso. Novamente, uma contradição do discurso médico: tanto a falta como o excesso de exercício da sexualidade feminina poderiam ser causa e consequência de doença mental (Engel, 2008). Tal constrição regulava o comportamento sexual das mulheres, fazendo com que sua sexualidade ficasse reclusa ao ambiente doméstico, a serviço do marido. Conforme Perrot (2008): “Misteriosa, a sexualidade feminina atemoriza. Desconhecida, ignorada, sua representação oscila entre dois polos contrários: a avidez e a frigidez. No limite da histeria" ( $p$. 65).

É justamente na histeria que veremos a relação mais estreita entre a anatomia feminina e a doença mental. Através dessa relação, revelase o processo de patologização do corpo feminino, de suas emoções e desejos (Engel, 2008; Perrot, 2008). No século XIX, a histeria foi descrita como uma doença eminentemente feminina (chegou-se a acreditar que o mal histérico provinha do útero), atada às características naturais da mulher. Aquela que padecia de histeria era considerada hiperssexualizada e pervertida, sendo o período mais propício para o aparecimento da doença aquele entre a puberdade e a menopausa. A histeria reafirmava a instabilidade feminina e a aura de mistério em torno da mulher, desafiando os saberes psiquiátricos (Engel, 2008). Em suma, o imbricamento entre o feminino e a histeria é sintetizado pela frase do psiquiatra UlysseTrélat, citado por 
Engel (2008): “Toda mulher é feita para sentir, e sentir é quase histeria" (p. 357).

Contudo, assumir a proposta de ir além do essencialismo significa também não conceber a mulher como categoria monolítica, como se todas as mulheres fossem iguais e houvesse uma homogeneidade de experiências e histórias femininas. A visão crítica quanto a isso partiu principalmente das feministas negras norte-americanas como Hooks (2013) e Crenshaw (2002) que denunciaram um feminismo branco e heterossexual que não contemplava todas as mulheres. Assim, é preciso analisar mais especificamente a experiência das mulheres negras e/ou pobres no Brasil.

A análise da história das mulheres negras e/ou pobres no Brasil desvirtua a naturalização das diferenças de gênero. Diversas historiadoras (Dias, 2012; Fonseca, 2008; Nepomuceno, 2012; Soihet, 2008) que se detiveram na investigação desses estratos populacionais demonstraram que o padrão feminino imposto às mulheres brancas burguesas não se adequava à realidade das mulheres negras e/ou pobres. As características ditas como naturais não eram correspondidas pelas mulheres do mesmo período histórico e que ocupavam o mesmo espaço geográfico.

Como diferença marcante temos que, ao passo que as mulheres brancas do século XIX restringiam-se a pequenos trabalhos domésticos e cuidados com os filhos, as mulheres mais pobres já trabalhavam fora de casa e, nessa medida, ocupavam o espaço público (Fonseca, 2008; Nepomuceno, 2012; Soihet, 2008). Ademais, os arranjos familiares também não eram aqueles da família nuclear burguesa. Como assegura Rachel Soihet (2008): “Eram mulheres que trabalhavam e muito, em sua maioria não eram formalmente casadas, brigavam na rua, pronunciavam palavrões, fugindo, em grande escala, aos estereótipos atribuídos ao sexo frágil" [grifo da autora] (p. 367).

Fonseca (2008) se detém na história das mulheres pobres no início do século XX no Brasil e em seus arranjos familiares. Segundo a historiadora, a migração dos homens em busca de emprego deixava as mulheres em situação de abandono, o que as levava ao trabalho. Contudo, mesmo aquelas que possuíam companheiro encaravam o trabalho como uma alternativa para a melhoria das condições de vida. Apesar dessas diferenças entre os estratos sociais femininos, a cobrança quanto à moralidade e ao controle das mulheres não fazia distinções quanto à classe ou etnia: só que, enquanto a mulher burguesa estava sujeita ao controle dos familiares homens, as mulheres pobres, em acréscimo, também sofriam com a vigilância da polícia e do sistema judiciário que tentavam instituir a moral burguesa no espaço público (Fonseca, 2008; Soihet, 2008).

Segundo Soihet (2008), após o período de escravização, o trabalho livre das camadas populares passou a ser objeto de disciplinarização, 
assim como outros aspectos da vida. A historiadora explica que o padrão burguês era exigido às demais camadas, já que o capitalismo se organizava contando com o trabalho doméstico das mulheres. Tal exigência se fazia com o aval da ciência, que justificava o trabalho "eminentemente feminino" como natural.

Esse controle do espaço público também se refletia quanto às moradias populares. O processo de urbanização brasileiro da época tinha a França como modelo. A circulação dos pobres pelas ruas comprometia esse ideal, bem como a existência das moradias populares. A retirada dessa camada populacional do centro da cidade prejudicava ainda mais as mulheres que tinham no local de moradia não apenas o exercício de seu trabalho (lavadeiras, engomadeiras, cozinheiras etc.), mas também uma rede de colaboração que garantia a sua sobrevivência e de sua família. Assim, se, para as mulheres burguesas, a rua era proibida, isso se acentuava ainda mais com as mulheres pobres, que "maculavam" a via pública com seus costumes, suas vestes: em suma, com suas existências (Nepomuceno, 2012; Soihet, 2008).

A dinâmica familiar também diferia do padrão burguês. Era corrente o número de famílias lideradas apenas por mulheres: em torno de $40 \%$ das famílias nesse período (Fonseca, 2008; Soihet, 2008). Os casamentos oficiais não eram a norma, a família assumia várias configurações, podendo haver recasamentos com ou sem a integração dos filhos dos cônjuges ao grupo familiar; os filhos "ilegítimos" e as relações sexuais antes do casamento também eram comuns (Fonseca, 2008; Soihet, 2008).

Contudo, as classes mais pobres não escapavam à moral burguesa dentro de seu próprio estrato social (Fonseca, 2008; Soihet, 2008). O desejo do casamento formal e as exigências da comunidade quanto a uma maior constrição moral das mulheres casadas se faziam presentes (Soihet, 2008). A virgindade, por exemplo, era tida como "patrimônio familiar" (Fonseca, 2008, p. 530). As moças desvirginadas que engravidavam podiam se submeter a abortos, matar a criança, se matar ou serem assassinadas na tentativa de preservar a honra familiar (Fonseca, 2008; Soihet, 2008). Por outro lado, a prostituição também aparecia como alternativa para algumas mulheres perante a pobreza e aos salários baixos das demais ocupações (Fonseca, 2008).

A retomada histórica fornece uma breve perspectiva da contribuição da ciência na produção de uma série de discursos que circulam/circularam socialmente e participam/participaram na construção do eu feminino:

[...] embora criado no interior das comunidades acadêmicas, o discurso acadêmico raramente permanece em casa. Ou seja, tal discurso é injetado (às vezes, sistematicamente) na cultura 
ambiente. Ao empreender as tarefas de descrição, explicação, análise lógica e crítica, os acadêmicos estão, na realidade, oferecendo ao mundo formas de prática discursiva (Gergen, 1993, p. 63-64).

Assim, percebe-se como a ciência serviu historicamente para subjugar mulheres e manter o poder masculino, construindo narrativas que são/foram usadas contra as mulheres. O próprio termo "histérica", por exemplo, foi disseminado no senso comum,como sinônimo de desequilibrada, estigmatizando as reações emocionais das mulheres ou - pior - designando uma farsa e, assim, deslegitimizando um sofrimento. A condição de subjugação se assevera quando colocamos em foco a população negra, em especial as mulheres negras, marcadas tanto pelo machismo quando pelo racismo científico. Sobre isso, é importante pontuar a racionalidade científica se alicerça em cima da colonialidade eurocêntrica que demarca outras polaridades além daquelas sexistas: humano/não humano, racional/irracional, civilizado/não civilizado, de acordo com Alves, Jesus e Scholz (2015). Desse modo, aqueles que não correspondem ao padrão eurocêntrico são vistos como populações menores, que não detêm o saber e que devem se submeter à racionalidade científica (Alves, Jesus, \& Scholz, 2015).

O colonialismo também se expressa na valorização de um eu eminentemente individual, que constrói a si mesmo, característica que, ao contrário do que a cultura norte-americana faz crer, não é um valor universal presente em todas as culturas (Young-Eisendrath, 1993). Sobre a construção individual do eu, Polly Young-Eisendrath (1993) discorre mais diretamente sobre a constituição do eu feminino pelo patriarcado. A autora trata da falácia da construção individual do eu, que é uma posse e um projeto levado a cabo pelo próprio sujeito. Dessa forma, o eu se constrói no intercâmbio social. Assim, na definição de eu das mulheres, participariam os conceitos elaboradas sobre elas pelo sistema patriarcal. Nessa construção permanecem as visões dicotômicas entre homens e mulheres: os homens seriam poderosos, inteligentes, fortes e competentes e as mulheres seriam sua antítese. Como destaca Young-Eisendrath (1993), caso não corresponda a tais características, a mulher será taxada de agressiva, pouco feminina, autoritária, controladora e rígida; por outro lado, aquelas que se encaixam no citado perfil podem ser vistas como infantis, dependentes ou com algum tipo de déficit intelectual. Enquadrar-se em um contorno ou outro não se dá sem algum sofrimento ou cobrança da própria mulher quanto a si mesma, já que se percebe ora como inadequada, ora como inferior.

A autora destaca ainda o fato de que muitas doenças mentais podem ser descritas como "excesso de feminilidade": depressão, anorexia, bulimia, fobia, histeria. Além disso, padecer de um transtorno mental 
reforça um ciclo de estigmatização já que, por conta do estereótipo acerca das doenças mentais, é reforçada a percepção de fragilidade e instabilidade feminina (Young-Eisendrath, 1993).

Contudo, propondo um olhar interseccional entre gênero e raça, percebemos que a construção do eu das mulheres negras é ainda mais perversa que a das mulheres brancas, vistas como universais, o que invisibiliza a complexidade da produção da subjetividade da mulher negra. Para tanto, acreditamos que é válido transpor as discussões produzidas por Alves, Jesus e Scholz (2015) sobre os efeitos do racismo sobre a subjetividade dos homens e mulheres negros. Os autores discorrem que o paradigma colonial implica numa construção de uma subjetividade subalterna por parte da população negra, que se percebe como menor, em contraste com os brancos, o que os leva a adotar padrões de embranquecimento tanto físicos quanto culturais.

Todavia, é preciso salientar que as narrativas sobre o eu feminino produzidas pelo patriarcado não são as únicas possíveis: outras narrativas que não são hegemônicas também existem. Entendemos que apagar parte da história de um povo ou de um determinado estrato social se dá de maneira intencional, com intuitos de dominação e opressão. Além disso, apagar determinadas narrativas ou silenciá-las é ainda arruinar a identidade pessoal e, destarte, produzir processos de adoecimento. Sendo assim, na seção seguinte adotaremos outra perspectiva histórica, procurando ressaltar o protagonismo feminino.

\section{Por outra inscrição na história}

Você pode me inscrever na história Com as mentiras amargas que contar Você pode me arrastar no pó, Ainda assim, como pó, vou me levantar (Maya Angelou)

Se Solnit (2017) e Perrot (2008) falam do silenciamento feminino como forma de apagamento e subjugação, Susan Gal (1991), em texto sobre o uso da linguagem em relação ao gênero, nos traz outra forma de enxergar o silêncio. $O$ silêncio pode ser visto também como uma forma de protesto. Além disso, nas dinâmicas sociaiso poder circula, não se apresenta de maneira estanque. Assim, silenciar nem sempre está atrelado à submissão: em julgamentos, confissões e terapias, o poder costuma estar, justamente, naquele que escuta.

Especificamente sobre as mulheres, Gal (1991) discute algumas pesquisas que demonstram que a visão da mulher como figura passiva e sem voz pode estar equivocada. Ela nos fala sobre 
estratégias de comunicação que as mulheres adotam em determinados contextos culturais para driblar a centralidade masculina na sociedade: uso de ironia e linguagem ambígua, manejo de outra língua, produção de poesias críticas etc. Ademais, sobre as pesquisas antropológicas que encontraram resultados que corroboraram a baixa participação das mulheres em contextos públicos e seu provável silenciamento, Susan Gal (1991) assevera que vieses sexistas podem ter interferido nos resultados: de maneira geral, os antropólogos (homens) demonstram pouco interesse em pesquisar a participação das mulheres em outra cultura e o próprio gênero (masculino, no caso) pode servir também como uma barreira para a comunicação com as mulheres. A autora fala sobre as sutilezas das dinâmicas sociais em certos contextos culturais que muitas vezes podem não ser percebidas: em rituais religiosos e na participação política, homens e mulheres podem possuir papéis distintos, o que não necessariamente implica que as mulheres não ocupem o espaço público, mas sua participação pode estar relacionada a atividades expressivas ou de atuação nos bastidores de decisões políticas. Assim, apesar da hegemonia masculina nas esferas de poder, é preciso entender que as dinâmicas interacionais são mais complexas e que o silenciamento feminino não se dá de forma passiva ou automática por parte das mulheres.

Dessa maneira, o convite desta seção é ir além das polaridades que se apresentam de antemão, procurando compreender os fenômenos sociais por outro ângulo além daquele visto como inequívoco. Extrapolar as polaridades significa também conceber as relações entre mulheres e homens deslocadas da posição simplista vítimas/algozes (pois, em certa medida, isso mantém o binarismo de gênero), visando enxergar os meandros de oposição e resistência construídos pelas mulheres.

A própria luta feminista é um movimento de resistência ao patriarcado e através dela as mulheres alcançaram inúmeras conquistas. Concernente a isso, Nogueira $(2001,2012)$ identifica três ondas no movimento feminista: a primeira onda que se inicia no século XIX, com a reivindicação dos direitos civis e políticos das mulheres; a segunda onda nos anos 1960 até os anos 1980 (período marcado pelos movimentos pelos direitos civis), que sofre a influência das ideias do livro $O$ segundo sexo de Simone de Beauvoir e se caracteriza pela reivindicação por direitos reprodutivos, pela luta contra a violência sexual e de gênero e pelo questionamento da instituição familiar, o que em certa medida refletiu-se em leis de direito ao divórcio e na invenção da pílula contraceptiva; e a terceira onda, que a autora identifica como pós-feminismo, que vem com uma perspectiva crítica em relação ao feminismo de segunda onda, questionando o essencialismo e advogando a diversidade e a fragmentação identitária. Apesar dos textos que fazem um apanhado 
histórico do feminismo marcarem a presença das mulheres negras apenas na segunda e terceira onda do movimento, é preciso corrigir esse apagamento histórico.

Relativo a isso, Angela Davis (2016a) discorre sobre a participação das mulheres negras no movimento sufragista norte-americano, característico da primeira onda feminista. A autora descreve 0 movimento sufragista feminino norte-americano no século XIX como disperso: as mulheres da classe trabalhadora não compreendiam a importância do voto e preferiam se engajar em movimentos reivindicatórios por mais direitos trabalhistas, como o direito a compor os sindicatos e a equiparação salarial com os homens. Somente no início do século XX é que as mulheres trabalhadoras começaram a perceber que o voto poderia ser uma ferramenta na conquista de direitos trabalhistas. A despeito da postura racista (e também classista, a princípio) de algumas lideranças do movimento sufragista e da própria National American Woman Suffrage Association (Nawsa) como um todo, as mulheres negras também se fizeram presentes no movimento, em destaque Ida B. Wells, Mary Church Terrell e Mary McLeod Bethune. A Associação Nacional das Agremiações de Mulheres de Cor criou um departamento específico para discutir o sufrágio, mas a afiliação de mulheres negras à Nawsa foi rejeitada com a justificativa de que a adesão de negras poderia enfraquecer o movimento por conta do acentuado racismo presente no Sul dos Estados Unidos (Davis, 2016a).

A participação feminina também foi marcante no movimento antiescravagista norte-americano, contando com a presença tanto de donas de casa como de mulheres trabalhadoras. Em um período em que a mulher não podia se expressar em público, principalmente em plateias mistas, as mulheres fundaram associações de combate à escravidão como a Sociedade Antiescravagista Feminina da Filadélfia e a Sociedade Antiescravagista Feminina de Boston. Na oposição à escravidão, algumas mulheres se destacam como: Prundence Crandall, que desafiou a cidade de Canterburry ao aceitar ensinar uma menina negra em sua escola; Lucreccia Mott, que apoiou a fundação da Sociedade Antiescravagista Feminina da Filadélfia, enfrentou gangues racistas e ajudou escravos fugidos; as irmãs Sarah e Angelina Grimké, da Carolina do Sul, grandes oradoras em prol da causa antiescravista e entre as primeiras mulheres a compreenderam que lutar contra a escravidão era também reivindicar o espaço político feminino (Davis, 2016b).

O movimento antiescravagista oferecia às mulheres de classe média uma oportunidade de provar seu valor de acordo com parâmetros que não estavam ligados a seus papéis como esposas e mães. Nesse sentido, a campanha abolicionista era um espaço em que elas poderiam ser valorizadas por seu 
trabalho concreto. De fato, seu envolvimento político na luta contra a escravidão talvez tenha sido tão intenso, apaixonado e total porque podiam vivenciar uma estimulante alternativa à sua vida doméstica. E estavam resistindo a uma opressão que se assemelhava àquela que elas mesmas viviam. Além disso, no interior do movimento antiescravagista, aprenderam a desafiar a supremacia masculina. Ali, descobriram que o sexismo, que parecia inabalável no casamento, poderia ser questionado e combatido na arena da luta política. Sim, as mulheres brancas podiam ser instadas a defender intensamente seus direitos enquanto mulheres a fim de lutar pela emancipação do povo negro (Davis, 2016b, s.n.).

No contexto brasileiro, é válido retomar a história de resistência das mulheres negras escravizadas. Sobre a vida dos escravizados no Brasil rural, Maria Odila Dias (2012) afirma: "Seguir vivendo em ambiente tão hostil exigiu força, inteligência, capacidade de adaptação e, sempre que possível, rebeldia. É como se, a todo momento, fosse preciso inventar formas de não morrer, não adoecer e não enlouquecer enquanto serviam a seus senhores" (p. 360). Segundo Dias (2012), as mulheres escravizadas, além de sofrerem com os castigos impingidos aos homens escravizados, também sofriam em condição de seu sexo: golpes na barriga quando estavam grávidas, mantendo o mesmo ritmo de trabalho nessa condição; violências por parte dos companheiros motivadas por ciúmes, culminando até mesmo em assassinato; estupros cometidos por senhores e feitores; morte em virtude de complicações no parto devido à desnutrição, ritmo intenso de trabalho e agressões; separação dos filhos e familiares. Frente a esse contexto de extrema violência, uma forma de resistência possível era a fuga (embora mais difícil para aquelas que tinham filhos), mas elas também lançavam mão da magia e da religião como forma de proteção das crueldades. Era comum ainda o uso de estratagemas para enganar os senhores, como misturar o algodão com barro para que ganhasse mais peso, ou o envenenamento deles (Dias, 2012).

Entretanto, a forma mais eficaz de "resistência" era a compra da própria liberdade, o que era mais difícil para as mulheres escravizadas do meio rural, pois não tinham a possibilidade de atuar como escravas de ganho vendendo quitutes e outros alimentos na cidade. A compra da alforria era mérito da própria mulher. A alforria no século XIX em contexto urbano era predominantemente feminina. Contudo, a compra da alforria era possível com muito sacrifício e a liberdade não garantia uma vida tranquila, muitas eram confundidas com escravas fugidas, reescravizadas ou sofriam nas mãos dos maridos. Todavia, Dias (2012) ratifica que, apesar de todo o contexto de exploração e opressão, na pós-abolição, essas mulheres 
conseguiram conquistar posições na sociedade, trabalhando na produção de café e açúcar e, principalmente, em feiras e mercados de abastecimento.

Contudo, enxergar a resistência dessas mulheres não deve de forma alguma ser encarado de maneira romântica, mas como uma forma de desvelar uma suposta passividade feminina frente às adversidades, uma cristalização do papel de vítima. Se, conforme Dias (2012), as mulheres negras conquistaram seu espaço social pós-abolição, é preciso demarcar que se mantiveram em um espaço marginal, de trabalho subvalorizado, com menores salários que todos os estratos populacionais e muitas vezes sem direitos trabalhistas. Retomar a vida dessas mulheres permite também que compreendamos as raízes da nossa história de maneira tal que ações de reparação sejam delineadas, e que tomemos consciência de nossa condição de privilégio na intersecção de opressões.

Diferente da visão otimista de Dias (2012) sobre a ocupação do mercado de trabalho por parte das mulheres escravizadas no contexto pós-abolição, Nepomuceno (2012) nos fala da tentativa de embranquecer a população brasileira através da imigração de europeus para ocupar determinados postos de trabalho muitas vezes ocupados por elas:

Data também do Império a mentalidade de que os negros teriam um "caráter degenerado". Expressões como "alienado", "bêbado", "imoral" e "práticas bárbaras", associadas à população negra, tornaram-se cada vez mais frequentes nas diferentes seções dos jornais, intensificando-se ante a iminência da Abolição e o suposto acesso dos negros à cidadania. Uma vez abolida a escravidão, impuseram-se as dificuldades de inserção dos ex-escravos, homens e mulheres, na "nova" sociedade. Começa aqui, em evidente desvantagem, nossa História das mulheres negras (Nepomuceno, 2012, p. 385).

Quanto a seu papel familiar, as mulheres negras não eram esposas passivas, muitas eram responsáveis pelo sustento da família (como até hoje). Contudo, o peso da manutenção familiar acabava colocando-as num ciclo de vulnerabilidade já que não podiam prescindir do trabalho e não tinham acesso à educação. Uma forma de romper com tal ciclo era investir na educação da geração subsequente. Neste sentido, os movimentos negros arrojaram-se na educação de seus pares, muitas vezes fundando escolas, pois não havia apoio do Estado. Outra maneira que a população negra encontrou de fazer frente às iniquidades sociais e ao racismo foi através da criação de associações e jornais negros, espaços onde as mulheres negras eram maioria, apesar de ocuparem função 
subalterna aos homens. Nessa direção, destacam-se: a Frente Negra Brasileira criado em 1931, com duas ramificações femininas responsáveis pelo jornal A voz da raça; o Conselho Nacional das Mulheres Negras que surgiu por volta de 1950, com grande adesão de empregadas domésticas; e, em 1978, o Movimento Negro Unificado contra a Discriminação Racial (MNU), tendo como uma das fundadoras Lélia González, uma das responsáveis pelo enegrescimento do feminismo brasileiro (Nepomuceno, 2012).

Como forma de oposição frente ao paradigma colonialista instituído, Alves, Jesus e Scholz (2015) discorrem sobre o paradigma da afrocentricidade. A afrocentricidade assume que não há conhecimento neutro, que toda forma de saber se constrói em um dado contexto histórico cultural e, muitas vezes, em detrimento de outro saber. Assim, buscando superar a visão do negro como não-humano "A afrocentricidade é entendida como um tipo de pensamento, prática e perspectiva que percebe os africanos como sujeitos e agentes de fenômenos atuando sobre sua própria imagem cultural e de acordo com seus próprios interesses humanos" (Asante, 2009, p. 93 como citado em Alves, Jesus, \& Scholz, 2015, p.872).

Entendemos que assumir um paradigma afrocentrado, bem como outras construções narrativas, como vem sendo discutido aqui, alinha-se à perspectiva construcionista de desfamiliarização do que está posto, de ressignificação contínua do que foi naturalizado, possibilitando assim a construção de novos sentidos (Spink \& Frezza, 2013). Ademais, acreditamos que com a assunção de outras narrativas abre-se a possibilidade de novas construções de eu femininos (brancos, negros e de outros marcadores sociais que não foram discutidos aqui). Assumir uma perspectiva histórica ou outra é uma escolha parcial, crendo nisso podemos escolher se queremos uma história que produz identidades adoecidas ou outra na qual podemos experimentar construções mais salutares.

\section{Considerações finais}

A discussão produzida neste texto buscou fazer uma retomada histórica dando visibilidade às questões que foram, em certa medida, apagadas da história oficial. Cremos que o apagamento de parte da história de um povo ou de um determinado estrato social se dá de maneira intencional, com intuitos de dominação e opressão. Além disso, destruir certas narrativas ou silenciá-las é ainda arruinar a identidade pessoal de um determinado grupo, e, destarte, contribuir para a produção de processos de patologização, marginalização e de adoecimento.

O saber médico-científico do século XIX, dominado pelos homens e em aliança com o moralismo, tinha o corpo masculino como norma. 
Visto com suspeição, o corpo feminino passou a ser patologizado e medicalizado, o que se deu em sintonia com uma visão essencialista da mulher: aquelas que desvirtuavam sua "essência" eram consideradas loucas. Ademais, a adoção de narrativas patriarcais e coloniais eurocêntricas contribuem/contribuíram para a construção de uma visão de menor valia das mulheres e dos negros e, mais ainda, quando se dá a intersecção entre os dois marcadores sociais, no caso das mulheres negras. Entre as consequências disso, no contexto nacional, segundo estudo da Flacso Brasil (Waiselfisz, 2015), estão o alto índice de homicídios de mulheres, o que se assevera entre as mulheres negras: o Brasil ocupa a 5o posição no ranking mundial de homicídio de mulheres segundo dados da Organização Mundial de Saúde, com taxa de 4,8 homicídios por 100.000 mulheres; e, enquanto o número de homicídios de mulheres brancas caiu no período pesquisado (2003-2010), entre as mulheres negras houve um aumento de 19,5\% (Waiselfisz, 2015). Já a compreensão da relação entre os processos de adoecimento mental e as diferenças de gênero, raça/cor e classe social nos parecem mais complexas e nebulosas devido à própria multideterminação dos transtornos mentais. Nesse sentido, acreditamos que seria válido recorrer às autonarrações das mulheres, aquelas do tempo vivido e do tempo curto, que remetem ao processo de socialização e interação cotidiana, respectivamente (Spink \& Medrado, 2013).

Acreditamos que a retomada histórica permite perceber que determinadas crenças, valores e preconceitos foram estabelecidos historicamente, são construções sociais e, sendo assim, outras produções também são possíveis. Dar notoriedade a outras narrativas históricas é uma forma de desfamiliarizar o que é visto como dado, encarado como essência e universalizado. Demarcar que as mulheres têm/tiveram importante participação na história é também um movimento de resistência e fazer com que essas narrativas circulem socialmente já impulsiona um movimento de mudança social.

Esta contribuição crítica e historicamente situada também nos parece profícua para alicerçar estudos empíricos que tenham como ponto de partida de que o que se lê como doença mental pode ser também mais um modo de resistência, uma estratégia de sobrevivência para a restauração da saúde. Além disso, do ponto de vista metodológico, sugere um maior investimento nas autonarrações das próprias mulheres como uma alternativa para abordar tais condições de produção da relação entre saúde mental e gênero. Este tem sido o pressuposto epistêmico e metodológico do projeto de tese que temos desenvolvido, intitulado "Narrativas de mulheres em sofrimento mental: reflexões a partir da Psicologia Social Construcionista".

Por fim, vale salientar que o que chamamos de eu feminino, apesar do termo remeter a uma essencialidade, surge como forma de especificar que os papéis sociais construídos para homens e 
mulheres, pelo menos até então, são distintos, o que acaba repercutindo na forma que algumas mulheres expressam seu gênero e são mais ou menos identificados socialmente como mulheres. Mas, posto que tais distinções são construções sociais, podem ser reconfiguradas. Cremos que as narrativas de resistência das mulheres que discorremos no ensaio abrem a possibilidade de construção de um eu menos normativo, com diferenças entre os gêneros menos cristalizadas e que se opõe a uma patologização do feminino, o que se torna ainda mais consistente quando propomos um olhar que desvela a diversidade de experiências femininas. Parafraseando Maya Angelou no poema que nos serviu de título, que nos levantemos em busca de novas narrativas, novas possibilidades de ser mulher, deixando para trás o terror e a atrocidade, em busca de um novo dia.

\section{Referências}

Alves, M. C., Jesus, J. P., \& Scholz, D. (2015). Paradigma da afrocentricidade e uma nova concepção de humanidade em saúde coletiva: reflexões sobre a relação entre saúde mental e racismo. Saúde em Debate, 39(106), 869-880. doi: 10.1590/0103-1104201510600030025

Brockmeier, J., \& Harré, R. (2003). Narrativa: problemas e promessas de um paradigma alternativo. Psicologia: Reflexão e Crítica, 16(3), 525-535. doi:10.1590/S010279722003000300011

Castañon, G. A. (2004). Construcionismo social: uma crítica epistemológica. Temas em Psicologia da SBP, 12(1), 67-81.

Crenshaw, K. (2002). Documento para o Encontro de Especialistas em Aspectos da Discriminação Racial Relativos ao Gênero. Revista de Estudos Feministas, 10(1), 171-188.

Davis, A. (2016a). Mulheres trabalhadoras, mulheres negras e a história do movimento sufragista. In A. Davis, Mulheres, raça e classe[online]. São Paulo: Boitempo. Recuperado de https://coletivoanarquistalutadeclasse. files. wordpress.com/201 $0 / 11 /$ mulheres-raca-e-classe-angela-davis.pdf

Davis, A. (2016b). O movimento antiescravagista e a origem do direito das mulheres. In A. Davis, Mulheres, raça e classe[online]. São Paulo: Boitempo. Recuperado de https://coletivoanarquistalutadeclasse. files. wordpress.com/201

$0 / 11 /$ mulheres-raca-e-classe-angela-davis.pdf

Dias, M. O. (2012). Escravas: resistir e sobreviver. In C. B. Pinsky, \& J. M. Pedro (Orgs.), Nova história das mulheres no Brasil (pp. 360-381). São Paulo: Contexto, 2012. 
Engel, M. (2008). Psiquiatria e feminilidade. In M. Del Priori (Org.), História das mulheres no Brasil (pp. 322-361). São Paulo: Contexto.

Fonseca, C. (2008). Ser mulher, mãe e pobre. In M. Del Priori (Org.), História das mulheres no Brasil (pp. 510-553). São Paulo: Contexto.

Gal, S. (1991). Between speech and silence: the problematics of research on language and gender. In M. Di Leonardo (Ed.), Gender at the crossroads of knowledge: feminist anthropology in the postmodern era (pp. 175-202). California, Berkeley: University of California Press.

Gergen, K. (1998). Narrative, moral identity and historical consciousness: a social constructionist account. Recuperado de https: //pdfs. semanticscholar.org/84a2/4510c02cf02045ebecdfa 135a09e2cf68230. pdf

Gergen, K. (2011). Realidades y relaciones: aproximaciones a la construcción social. Barcelona: Paidós.

Hooks, B. (2013). Estudos feministas. In B. Hooks. Ensinando a transgredir: a educação como prática da liberdade. São Paulo: Martins Fontes.

Méllo, R. P., Silva, A. A., Lima, M. L. C., \& Di Paolo, A. F. (2007). Construcionismo, práticas discursivas e possibilidades de pesquisa em psicologia social. Psicologia \& Sociedade, 19(3), $26-32$.

Nepomuceno, B. (2012). Mulheres negras: protagonismo ignorado. In C. B. Pinsky, \& J. M. Pedro (Orgs.). Nova história das mulheres no Brasil (pp. 382-409). São Paulo: Contexto.

Nogueira, C. (2001). Feminismo e Discurso do Género na Psicologia Social. Psicologia e Sociedade, (13), 1-28. doi:10.1590/S010237722008000200014

Nogueira, C. (2012). O gênero na psicologia social e as teorias feministas. Dois caminhos entrecruzados. In F. T. Portugal, \& A. M. Jacó-Vilela (Orgs.). Clio-psyché: gênero, psicologia, história (pp.43-67). Rio de Janeiro: NAU.

Oliveira, L. S., \& Jacó-vilela, A. M. (2017). A mulher nas narrativas do saber médico na transição entre os séculos XIX e XX. Quaderns de Psicologia, 19(3), 241-251. doi: $10.5565 /$ rev/qpsicologia. 1390

Perrot, M. (2008). Minha história das mulheres. São Paulo: Contexto.

Rasera, E. F., \& Japur, M. (2005). Os sentidos da construção social: o convite construcionista para a Psicologia. Paidéia, 15(30), 2129.

Rohden, F. (2012). Narrativas científicas e definição de identidades: a questão de gênero e a ênfase no biológico. In F. T. Portugal, \& A. M. Jacó-Vilela (Orgs.), Clio-psyché: gênero, psicologia, história (pp. 69-90). Rio de Janeiro: NAU. 
Shotter, J., \& Logan, J. (1993). A penetração do patriarcado: sobre a descoberta de uma voz diferente. In M. M. Gergen (Ed.), O pensamento feminista e a estrutura do conhecimento. Rio de Janeiro: Rosa dos Ventos/Edunb.

Soihet, R. (2008). Mulheres pobres e violência no Brasil urbano. In M Del Priori (Org.), História das mulheres no Brasil. São Paulo: Contexto.

Solnit, R. (2017). Uma breve história do silêncio. In R. Solnit, A mãe de todas as perguntas: reflexões sobre os novos feminismos. São Paulo: Companhia das Letras.

Spink, M. J. P. (2010). Linguagem e produção de sentidos no cotidiano. Rio de Janeiro: Centro Edelstein de Pesquisas Sociais.

Spink, M. J., \& Frezza, R. M. (2013). Práticas discursivas e produção de sentido: a perspectiva da psicologia social. In M. J. Spink (Org), Práticas Discursivas e Produção de Sentido no Cotidiano: aproximações teóricas e metodológicas (pp. 01-21). Rio de Janeiro: Centro Edelstein de Pesquisas Sociais.

Spink, M. J., \& Medrado, B. (2013). Produção de sentido no cotidiano: uma abordagem teórico-metodológica para análise das práticas discursivas. In M. J. Spink (Org), Práticas Discursivas e Produção de Sentido no Cotidiano: aproximações teóricas e metodológicas (pp. 22-41). Rio de Janeiro: Centro Edelstein de Pesquisas Sociais.

Waiselfisz, J. J. (2015). Mapa da violência 2015: homicídios de mulheres no Brasil [online]. Brasília: Flacso Brasil. Recuperado de http://www.mapadaviolencia.org.br/pdf2015/MapaViolencia_20 15 mulheres. pdf

Young-Eisendrath, P. (1993). A pessoa do sexo feminino e como falamos dela. In M. M Gergen (Ed.), O pensamento feminista e a estrutura do conhecimento. Rio de Janeiro: Rosa dos Ventos/Edunb.

Yousafzai, M. (2013). Eu sou Malala: a história da garota que defendeu o direito à educação e foi baleada pelo talibã. São Paulo: Companhia das Letras.

\section{Endereço para correspondência}

Ana Carolina Cerqueira Medrado

Universidade Federal da Bahia

Programa de Pós-Graduação em Psicologia

Rua Aristides Novis, 197, Est. de São Lázaro, CEP 40210-630, Salvador - BA, Brasil Endereço eletrônico: accm100@yahoo.com.br

Mônica Lima de Jesus

Universidade Federal da Bahia

Instituto de Psicologia

Rua Aristides Novis, 197, Est. de São Lázaro, CEP 40210-630, Salvador - BA, Brasil 
Endereço eletrônico: molije@hotmail.com

Recebido em: 17/12/2018

Reformulado em: 22/02/2019

Aceito em: 15/03/2019

\section{Notas}

* Psicóloga; especialista em saúde mental na modalidade Residência Multiprofissional em Saúde- UNEB; mestra em Saúde, Ambiente e Trabalho - UFBA; doutoranda em Psicologia Social - UFBA.

** Psicóloga; Professora Associada III; Doutora em Saúde Coletiva - UFBA; PósDoutorado em Psicologia Social- Universidade Autônoma de Barcelona.

${ }^{1}$ Título inspirado no poema Still I Rise, de Maya Angelou.

${ }^{2}$ Ainda assim me levanto, tradução de Francesca Angiolillo do poema Still I Rise, de Maya Angelou, disponível em https://www1.folha.uol.com.br/ilustrada/2014/05/1461284-leia-traducao-dopoema-still-i-rise-de-maya-angelou.shtml. Acesso 07/08/2018. As demais epígrafes se referem a trechos do mesmo texto.

Financiamento: Coordenação de Aperfeiçoamento de Pessoal de Nível Superior (CAPES)

Este artigo de revista Estudos e Pesquisas em Psicologia é licenciado sob uma Licença Creative Commons Atribuição-Não Comercial 3.0 Não Adaptada. 